\title{
NUEVAS PERSPECTIVAS SOBRE LA CRISIS DEL SIGLO XVII EN CASTILLA*
}

DAVID R. RINGROSE

Univ. de California. San Diego

La historiografía de la vida política y económica europea ha estado dominada durante muchas generaciones por el espectro de una crisis general en el siglo XVII. El libro de Roger Merriman Six Contemporaneous Revolutions ${ }^{1}$ evocaba la idea de crisis en términos de seis grandes revoluciones políticas que abarcaron todo el continente a mediados de siglo. Las primeras ediciones de La Mediterranée et le monde mediterranéen ${ }^{2}$ y la monumental obra de los Chaunu, Seville et l'Atlantique ${ }^{3}$, respaldada esta última por el libro de Earl Hamilton, American Treasure and the Price Revolution in Spain ${ }^{4}$, dieron dimensión económica al concepto de crisis y concentraron además el enfoque sobre la región mediterránea y sobre la península ibérica.

El concepto de crisis fue dotado de un marco de referencia general europeo con la magistral obra de B. H. Slicher van Bath, The Agrarian History of Western Europe, aparecido en $1963^{5}$. Slicher van Bath integró toda una serie de problemas

* Nota sobre The Castilian Crisis of the Seventeentb Century: New Perspectives on the Economic and Social History of Seventeentb-Century Spain. Edición a cargo de I. A. A. Thompson y Bartolomé Yun Casalilla. Cambridge: Cambridge University Press, 1994. Publicado en asociación con el Instituto de Estudios Fiscales, Madrid. Pp. xiv +328 .

Roger Merriman, Six Contemporaneous Revolutions (Oxford: The Clarendon Press, 1938).

2 Fernand Braudel, La Mediterranée et le monde mediterranéen á l'epoque de Philippe II (París: A. Colin, 1949).

'Huguette y Pierre Chaunu, Seville et l'Atlantique, 1504-1650 (8 vols., París: A. Colin, 1955-1959).

Earl J. Hamilton, American Treasure and the Price Revolution in Spain, 1501-1650 (Cambridge:

Harvard University Press, 1934).

' B. H. Slicher van Bath, The Agrarian History of Western Europe, A. D. 500-1850 (Londres: E. Arnold, 1963). 
diversos en una síntesis extraordinaria, en la que trató temas tan variados como las formas de adaptación de Europa a la peste bubónica en la era postromana, los metales preciosos americanos, la expansión del comercio europeo, las tendencias climáticas, los cambios en tecnología agrícola, y el dominio de la tierra. La argamasa que unía todo el proyecto era el modelo neomalthusiano de cambio demográfico y su interacción con la oferta de tierra y el problema de los rendimientos decrecientes en una era de tecnología agrícola estática o en lenta evolución. En el modelo de Slicher van Bath se integraban estas consideraciones de tipo teórico con los datos empirícos a los que tuvo acceso en una amagalma de la cual se desprendía una crisis económica general en Europa en el siglo XIV y otra crisis similar en el siglo XVII.

Desde la publicación del libro de Slicher van Bath y la posterior aparición de Crisis in Europe, 1560-1660 en $1965^{\circ}$, una generación entera de historiadores ha ido gradualmente ampliando y desmantelando después la idea de «crisis general». Las fluctuaciones detectadas en el volumen de metales preciosos y en el comercio atlántico han sido cuestionadas por la investigación de nuevas fuentes archivísticas. La crisis comercial de principios del siglo XVII se ha transmutado en un desplazamiento del locus de los mercados comerciales que integraban dicho comercio. La crisis demográfica general ha pasado a ser una cuestión con amplia variedad de situaciones y cronologías locales y regionales.

Además, el modelo neomalthusiano de presión demográfica y productividad marginal descendente se ha enriquecido de diversas maneras. Este hecho queda gráficamente ilustrado por la variedad de enfoques de la colección de ensayos contenidos en The Brenner Debate ${ }^{7}$. La función del control social en la redistribución de la renta, apartándola de los sectores más pobres de la sociedad rural y depositándola en manos de diversas elites por vía de los arrendamientos, la apropiación particular de recursos comunales, el aumento de los impuestos, y una compleja multiplicación de capas de endeudamiento y servicio de deuda, real, provincial y municipal, son aspectos que han sido convincentemente documentados. De manera similar, las ventajas de la especialización regional y la integración del mercado permitieron la capitalización e intensificación de fincas de tamaño mediano en muchas regiones. Por último, se ha puesto en cuestión el carácter monolítico de la «familia campesina autosuficiente» con la hipótesis de que las estrategias familiares de supervivencia alentaban en realidad a sus diversos miembros a responder a los incentivos del mercado con considerable presteza ${ }^{8}$.

'T Trevor Aston (ed.), Crisis in Europe, 1560-1660 (Nueva York: Basic Books, 1965).

T. H. Aston y C. H. E. Philpin (eds.), The Brenner Debate: Agrarian Class Structure and Economic Development in Pre-Industrial Europe (Cambridge: Cambridge University Press, 1985).

" Véase, por ejemplo, Jan de Vries, «The Industrious Revolution and the Industrial Revolution», Journal of Economic History, vol. 54 (1994). 
A lo largo de esta gradual reconstrucción de nuestra percepción de ese siglo de crisis que fue el xVII, realizada en buena medida por historiadores anglo-americanos y franceses, dos cosas quedan de relieve: han sido contadas las voces oídas en el debate que hablaban castellano; además, la mayoría de los participantes en el debate han tratado a España como una sola entidad económica que sufrió una gran crisis demográfica y política, más grave que la que aquejó a otros lugares de Europa occidental. El corolario de este estereotipo era el supuesto de que España se había sumido en una actitud de estancamiento económico, impotencia política y aislamiento cultural que la diferenciaba del mundo más rico y dinámico del norte y el oeste de Europa, convirtiéndola, como la Turquía del siglo XIX, en el eterno «enfermo de Europa» ${ }^{9}$. Las implicaciones a largo plazo de esta construcción historiográfica han configurado la mayoría de las interpretaciones de la España posterior al siglo XVII, un proceso que se ha entrelazado con la tendencia a encontrar explicaciones cómodas para todo el posterior desastre español en la crisis del siglo XVII. Las dimensiones de esta percepción histórica son en exceso voluminosas para poder tratarlas aquí, pero forman parte esencial del contexto historiográfico que convierte el libro de Yun y Thompson en una importante contribución tanto a la historia europea como a la española.

Su importancia se plasma en varios niveles. En el nivel inmediato, típico de esta clase de crítica de libros, es que reúne en un solo volumen una amplia selección de artículos y ensayos de historiadores españoles dedicados a España. Publicados en origen en lugares dispersos, todos estos trabajos formaron parte de un debate continuo sobre diversas facetas del siglo Xvil. Al publicarlos conjuntamente, en el contexto de las excelentes introducción y conclusión de Bartolomé Yun, la colección deja muy claro para el mundo anglófono algo que los historiadores españoles habían sospechado hacía tiempo: que España, e incluso una región como Castilla la Vieja, es grande en términos europeos y consecuentemente diversa en sus pautas locales de cambio demográfico, cambios en el acceso a la tierra, sensibilidad y contacto con las fuerzas de mercado, y ajuste al cambio económico interno y externo. Simultáneamente, las generalizaciones sobre la relación entre crisis económicas y agrarias y controles malthusianos a la peste, el papel del comercio colonial en la economía peninsular y el impacto del descenso en la entrada de metales preciosos resultan al fin simplistas e insustanciales.

Así, Ángel García Sanz y Vicente Pérez Moreda cuestionan ideas muy arraigadas sobre los vínculos causales entre las tendencias del siglo XVII y la peste por un lado y

צ Para un ejemplo clásico, véanse las referencias a España en Immanuel Wallerstein, The Modern World System, vol. I, Capitalist Agriculture and the origins of the European World-Economy in the Sixteentb Century; vol. II. Mercantilism and the Consolidation of the European World-Economy (New York: Academic Press, 1974, 1980). 
las reformas regias por otro. Gonzalo Anes y Enrique Llopis Agelán, aunque difieren en cuanto a la utilidad del término «crisis», rechazan la idea de un declive agrícola monolítico, aunque Llopis documenta de manera convincente la contracción de la agricultura y la privatización paralela de recursos comunales en manos de los señores. L. M. Bilbao y E. Fernández de Pinedo demuestran que había partes de la economía rural estrechamente ligadas a los mercados exteriores de lana, un factor que incidió de manera sostenida sobre el cambio de relación entre agricultura y pastoreo. Al mismo tiempo, A. García-Baquero nos muestra que el famoso comercio de Indias fue insignificante en tanto que explicación de las tendencias agrícolas de Andalucía. Sin decirlo explícitamente, José Ignacio Fortea Pérez demuestra también que el estancamiento de la industria textil de Córdoba fue parcialmente consecuencia de la marginalización de Andalucía en la economía de mercado europea.

La anómala pauta de urbanización castellana está ilustrada por Alberto Marcos Martín cuando traza la historia de Medina del Campo como centro urbano después que su función a larga distancia - las ferias mercantiles anuales-- quedara desfasada. Juan Gelabert sitúa esto en un contexto más amplio y examina la pauta de la decadencia urbana en todo el interior. Así, nos muestra que los impuestos, el cambio en las opciones de inversión de la elite, y la mayor autonomía institucional de las ciudades pequeñas en la segunda mitad del siglo XVII inhibieron la reurbanización en el siguiente siglo, incluso después que la población regional hubiera sobrepasado a la del siglo XVI. Finalmente, Felipe Ruiz Martín, José Manuel de Bernardo Ares, Ignacio Atienza Hernández y Bartolomé Yun exploran diversos aspectos del crecimiento de la monarquía central y la relación simbiótica que se desarrolló entre la Corona y la clase señorial. Los tradicionales controles sobre la sociedad rural se fueron afianzando progresivamente con el desempeño de cargos públicos, el dominio de los gobiernos municipales y la adquisición de censos, cuyos intereses se pagaban recurriendo a los impuestos recaudados entre los miembros menos privilegiados de la sociedad.

En la visión colectiva que emerge de todo esto, la «crisis de la Castilla del siglo XVII» no desaparece exactamente, pero sí queda fuertemente transformada. El determinismo malthusiano está intensamente enriquecido con diversos aspectos de la acción humana y un cuadro muy matizado de la cambiante relación tripartita entre la Corona, la elite terrateniente y la sociedad rural. El hecho de la crisis no desaparece del todo, pero deja de ser el problema más interesante. Simultáneamente, las cuestiones de la decadencia y el estancamiento también permanecen como parte del panorama, pero son a su vez relegadas al trasfondo en aras de un examen del proceso de «ajuste», donde siguen operando las fuerzas dinámicas de la sociedad.

Esta clase de observaciones sobre la diversidad regional y, de manera especial, sobre las generalizaciones amplias, nos llevan a la importancia del libro en un 
segundo ámbito de mayores dimensiones: el mundo de los historiadores europeos, que pocas veces leen los libros de estudiosos publicados en castellano, y mucho menos en catalán. En sus esfuerzos por vincular España al resto de Europa, estos especialistas han recurrido a un pequeño número de libros publicados en inglés y francés, muchos de ellos escritos hace varios decenios o incluso varias generaciones. Los trabajos de Julius Klein (primeramente publicado en 1920) ${ }^{10}$ y Earl Hamilton (primera edición en 1927-1934) ${ }^{11}$ siguen reapareciendo, muchas veces incuestionados, con notable regularidad en los estudios sobre historia europea en lengua inglesa. Estos mismos historiadores abandonaron hace mucho tiempo la imagen de una crisis general europea, así como la idea de tendencias a escala nacional en Francia o Inglaterra. Ahora bien, cuando hablan de España, aunque es frecuente que conozcan el trabajo de Vilar sobre las tendencias de Cataluña ${ }^{12}$, siguen escribiendo en términos toscamente generales sobre las «crisis» española o castellana.

Esta descripción de la historiografía europea acaso parezca en exceso exagerada, sobre todo a la actual generación de historiadores ingleses, norteamericanos y franceses que estudian los comienzos de la era moderna en España. Con todo, este volumen de Yun y Thompson hace inaceptable cualquier uso futuro de amplias generalizaciones sobre «España» o «Castilla». Este trabajo, muy legible en un inglés en su mayoría bueno y claro, y basado en una investigación y unos análisis sofisticados, presenta a los historiadores europeos evidencia irrefutable de que Malthus, las ovejas y la plata no tienen, por sí solos, ni más (ni menos) capacidad explicativa cuando se aplican a España que cuando se aplican a otros lugares de Europa. En un examen más detallado, vemos que la mayor parte de las regiones de España estaban cambiando, como en todos sitios, sus formas de interacción con el mundo en general. Castilla, foco nominal del libro, se resiste a toda generalización y presenta un mosaico de diversas tendencias y ajustes regionales. Así pues, aunque de las cifras de población agregada cabría sacar la impresión de una severa y prolongada depresión, la realidad era que Castilla estaba respondiendo al cambio igual que el resto de Europa, y no como una sociedad en progresivo aislamiento sino como parte integral de la vida económica y cultural europea. Sólo cuando esta realidad sea asimilada por la historiografía europea podrá librarse la propia historia de Europa de algunas de las contradicciones interpretativas asociadas a España como parte esencial del continente.

${ }^{10}$ Julius Klein, The Mesta: A study in Spanish Economic History, 1273-1836 (Cambridge: Harvard University Press, 1920).

florecimiento del capitalismo y otros ensayos de bistoria económica (Madrid Revista de Occidente, 1948) incluye artículos publicados mucho antes de su famoso trabajo American Treasure.

12 Pierre Vilar, La Catalogne dans l'Espagne moderne: recherches sur les fondements economiques des structures nationales ( 3 vols., Paris: S.E.V.P.E.N., 1962). 
Finalmente, este volumen es importante en una tercera categoria, dado que refleja la reafirmación que en el siglo Xx hace España de su lugar en Europa. Todos los autores de este libro son españoles; sus trabajos, generalmente conocidos en España, han sido poco leídos fuera de ella. Su trabajo representa invariablemente una impresionante combinación de estudios realizados sobre base archivistica y de prácticas metodológicas y teóricas vigentes en Europa en el momento de publicación de cada colaboración. Esta observación no resulta en modo alguno sorprendente a los historiadores españoles, ni tampoco a la actual generación de especialistas en España de otros países. Pero otros historiadores europeos tendrían que cobrar conciencia de la celeridad con que el mundo intelectual español respondió a la terminación del sistemático intento del régimen franquista de sofocar la profunda vitalidad cultural del mundo académico español.

Traducción de Eva Rodríguez Halffter 